\title{
Flood Hazard Zone Modeling for Cadastral Plots in Ojców National Park in Poland
}

\author{
Izabela Piech*, Stanisław Bacior, Monika Mika \\ University of Agriculture in Krakow, Faculty of Environmental Engineering and Land Surveying, Poland
}

\begin{abstract}
The paper presents the stages of development of DTM for fragment of ONP (Ojcow National Park). Model was created in order to illustrate potential flood zones of river Pradnik. In subsequent stages of the development are shown: Basic concepts of subjects taken in the publication, characteristics of research object, methodology of DSM implementation, elements of flood zones and assessment of flooded plots devastation impact on their cadastral and landscape values. The advantage of the method is a low cost and short time of DTM creation based on aerial photographs. Created model has also a relatively high accuracy of elaboration. It is noteworthy that for the area being elaborated independent survey were performed using classical and modern technology methods. The work results will provide a base for further analysis in order to determine the flood zones for mountain rivers. Described problem will be the subject of subsequent papers by the authors.
\end{abstract}

\section{Introduction}

The aim of the publication is to describe the implementation methodology of DTM and DSM in ONP in Poland, with particular emphasis on the determination of the flood zones of the river Pradnik. The study area includes the Pradnik Valley. The coastline of the river that is the subject of research is variable along its length. It does not coincide with the evidence borders of the river. The specific character of field surveying work in ONP requires from the surveyor not only knowledge of surveying law, but also knowledge of the constraints in national parks. Methodology of classical field work consists in the use of different measurement techniques and the integration of acquired data. The terrain configuration makes it necessary to use different techniques and surveying equipment (e.g., tacheometry, GNSS). Presented in the paper method of relief elaboration did not require field survey, except an interview in order to determine the control photo points. The model was made on the basis of the pictures from photogrammetric flight. This method appears to be much more beneficial in terms of economic (cost and time) to develop. Accuracy of the method is more than sufficient to estimate the range of flood zones for flood protection of the selected area [1,2]. In the study the following research tools were used: digital photogrammetric station DELTA digital photogrammetric station DEPHOS, SURFER program, Microsoft Excel, and data from the Geoportal.

\section{Terminology from the scope of the research}

In the international terminology the Digital Terrain Model is defined as: "Numeric representation of the terrain surface, formed by a set of properly selected points on the surface and interpolation algorithms allowing to render it in a specific area" [3].

According to [4] of the fundamental problems associated with the digital terrain model are:

- the sampling problem - problem of proper selection of the characteristic points of the surface in order to get the best results while minimizing the amount of data,

- representation problem - the problem of surface reproduction on the basis of existing data.

In turn, from a technical point of creating DTM there are two basic types of models [4-7]:

- GRID model - in the form of a regular grid of squares supplemented by the characteristic points and skeletal lines,

- TIN model - in the form of an irregular triangle mesh.

Data to create a digital terrain model derived primarily from three sources $[8,9,11,12]$ :

- direct measurements,

- photogrammetric measurements,

- digitization of existing maps.

Occasionally also radar or laser altimetry are used. These techniques are mainly used for studies of geological models, drilling or seismic measurements.

The term flood zone means the extent of flood waters, determined on the basis of long-term historical data or theoretical considerations, that determine the probability of flood events or local flooding in the area [13]. There are direct and potential areas of risk.

\footnotetext{
* Corresponding author: rmpiech@,cyf-kr.edu.pl
} 
The first is the area immediately adjacent to rivers or streams and areas in the immediate vicinity of levees, where there is a threat that water on a higher level than their crown can pour over them. In turn, the potential risk areas include the areas exposed to the destructive activities of water in the case of loss or substantial damage to the embankment [14].

In the last decade in Poland, there has been an increase of rainfalls in the months from May to July. Most of the rainfalls are violent storms bearing damages of local range. Therefore, the municipalities in collaboration with the staffs of the flood hazard and public emergency services have made efforts to obtain in a short time graphic materials necessary to elaboration potential flood zones. Flood hazard maps in Poland are above all used for analyses of the risks and they facilitate local government decision-making on mitigating the effects of floods, if there are any [15]. The first phase of flood hazard mapping concerns acquisition of the historical data related to maximum river or watercourse floods. The second stage is to determine the water level elevation to receive as a result the profile for a given flow. Flood zone boundary is determined by the intersection of the water surface profile for a given flow rate and the Digital Terrain Model obtained e.g. by photogrammetric methods $[16,17]$. The resulting zones are also divided into the potential and direct danger zones. Final flood hazard maps are made on the basis of raster maps, surveying profiles and knowledge of hydrology $[18,19,20]$.

The smallest component of the map, showing the unit of land is a cadastral plot. The concept of a plot of land in Poland is defined by [21]. According to the Regulation on the registration of land and buildings a cadastral plot is a continuous area of land situated within the cadastral district, legally homogeneous, separated from the environment by means of boundary lines. Continuity (area consistency) of a plot means that it cannot be composed of two or more separate surface objects. Location within the cadastral districts guarantees that a graphic view of the plot is possible to be presented on a single sheet of cadastral map. In the case of extended objects (railroads, streams) parcels are determined in such way that their boundaries coincide with the boundaries of cadastral district. Legal uniformity of land is considered only within the visualized property rights in land and buildings (e.g. ownership, perpetual usufruct). The plot is defined in terms of geometry by its separation from the environment by boundary lines connecting borders breakpoints. Physically, in the boundary break down points boundary markers are placed and limit lines can be represented by objects like fences, walls of buildings, etc. By determining the boundaries of the cadastral plots, in the case of mutual intersection of railway lines, public roads, internal sea waters and inland flowing waters, the following rules are applied:

- internal waters and inland waters flowing, with the exception of water flowing through pipelines or covered channels divide railways and public roads into separate cadastral plots photogrammetric measurements,
- railway lines divide public roads into separate cadastral plots,

- public roads of higher category divide roads of lower category into separate cadastral plots.

The concept of the cadastral parcel is inseparable connected with the concept of the land use consistent mostly with the local land use plan or community development study [22].

According to the previously cited Regulation of the Minister of Regional Development and Construction dated. March 29, 2001 on the land and buildings cadaster - usage of land can be described as: agricultural land, forest land and wooded and shrub land and urbanized, land under water, orchards of the area less than 0.1000 ha and other land of the area. less than 0.0100 ha which is not shown in cadaster. The former can be divided into: "Arable land, orchards, durable meadows, permanent pastures, agricultural land built-up, land for ponds and ditches. Built-up areas and urbanized area are divided into: residential areas, industrial areas, other built-up areas, urban area, recreational areas, land mines and transportation land".

The quoted provision also defines arable land, which include land mechanically cultivated for production purposes, land used for the cultivation of wicker, hops, ornamental trees nurseries and fallows. Orchards - land of the area greater than 0.1000 hectares planted with fruit trees and bushes, fruit trees nurseries and vineyards. Permanent grassland is generally covered with long-term land vegetation such as grasses, legume plants and herbs, regularly mowed. Permanent pastures, as meadows, are covered with long-term plants, with the difference that they are not mowed but grazed. To the built-up agricultural land we include land occupied by residential buildings and other buildings used for agricultural production, with certain exceptions. Land under ponds are areas for reservoirs of water that are used for breeding and keeping fish (exceptions: lakes and retention reservoirs). The land under the ditches we include land occupied by drainage ditches.

\section{Characteristics of the investigated object}

The study area covers a part of the Prądnik river valley in the Ojców National Park and the agricultural area lying south of it. This area has an attractive landscape, and is lying close to the routes of historical Krakow in Poland. Valley is composed mainly of limestone from the period of the Upper Jurassic and Cretaceous. They were formed 150 million years ago, and their thickness reaches up to $200 \mathrm{~m}$. In some places they are covered with a layer of loess. In the limestones karst features developed very well, the effect of which is the creation of numerous caves (about 300), gorges and ravines with exsurgents, rock gates, spiers and island mountains of fantastic shapes. Rock formations protruding above the surface are composed of rocky limestone with high hardness and compactness, located between the softer limestone layers. The most common fossils are sponges and brachiopods, very seldom ammonites. 
The valley is the result of the erosive action of water flowing on its bottom. On the slopes of the valley terraces formed at different times of the formation of the valley can be observed. In Pieskowa Skała they are 12 and $40 \mathrm{~m}$ above the valley floor, in Ojców 30-40 m and $80 \mathrm{~m}$. On these terraces rise Ojców Castle and Pieskowa Skała Castle.

Prądnik Valley is widely recognized as the most beautiful valley of the entire Jura. Its biggest attractions are:

- Pieskowa Skała Castle and Ojców Castle,

- available to tourists Dark Cave with the Neanderthal campsite,

- rocks, among others: Hercules' Club, Wernyhora Rock, Deotyma Needle, Maiden Rocks, Glove, Łaskawiec, Cracow Gate,

- Museum of the Ojców National Park,

- Chapel "On The Water".

In the analyzed area of research can also be seen predominance of the summer precipitations over winter ones (Fig. 1). The months June, July and August (indicated in Fig. 2) are as much as $40 \%$ of annual precipitation. Recent years show a minimal decrease in the amount of precipitation. These statistics do not, however, take into consideration floodings occurring locally in the area as a result of extreme weather.

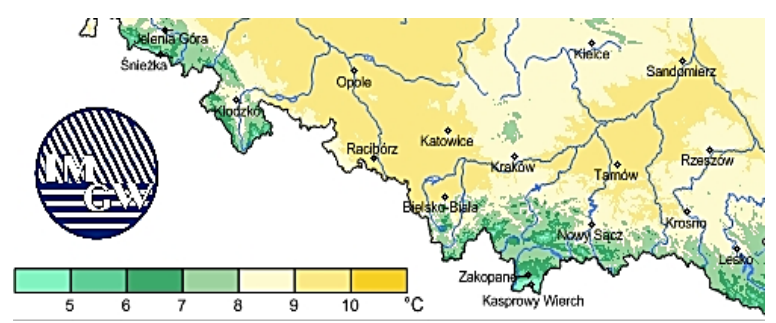

Fig. 1. Map of the temperature distribution of the studied region of Poland.

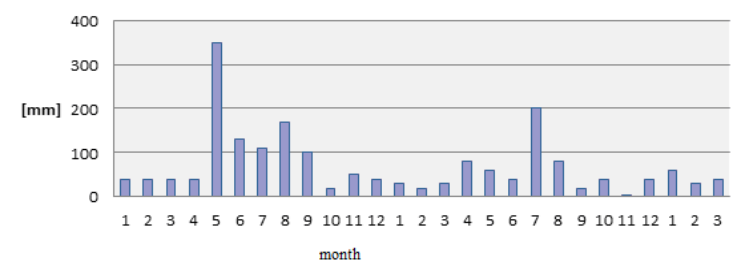

Fig. 2. Total rainfall for the investigated area in the years 2010, 2011 and 2012, drawn up on the basis of Polish climatic maps from the Institute of Meteorology and Water Management.

\section{Detailed methodology for development of DTM and DSM}

\subsection{The application of digital station "Delta"}

DTM is based on aerial stereograms in a scale 1:13000, made by RC20_13166 analog camera. Aerial photos in digital form were obtained from the Marshal's Office in Krakow. A digital photogrammetric station "Delta" was used for the elaboration. Below the various stages of the work with the use of specified materials are described.

\subsection{Creation of a project and data entry}

The development started with the creation of a new project in the Camera lap. Next data from metrics measuring camera were introduced (name of the camera, the focal length, the base of shooting, shifting the main coordinates of background stamps and the distortion). On the Ground lap control photo points coordinates, obtained from geodetic survey were entered. Due to the insufficient number of control points, for elaboration were used additional points derived from aerial triangulation or chamber densification of geodetic network. Obtaining of coordinates of the points was possible by the use of Dephos 4.10 software (Fig.3). The program initially converted a pair of images, then in the application Dephos Manager 4 batch file provided with aerial triangulation was placed, then using the Mapper Stereo lap all the points from the chamber densification of geodetic network were visualized.

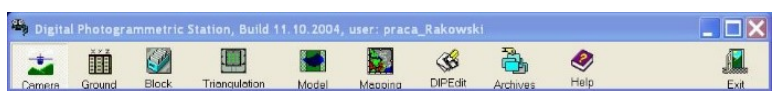

Fig. 3. Models Module Interface.

Then, in the application DEPEdit a pyramid of images was created. After entering the required data in the Models module - orientations of the photographs (internal, mutual, absolute) and stereograms vectorization (Mapping) were performed (Fig.4).

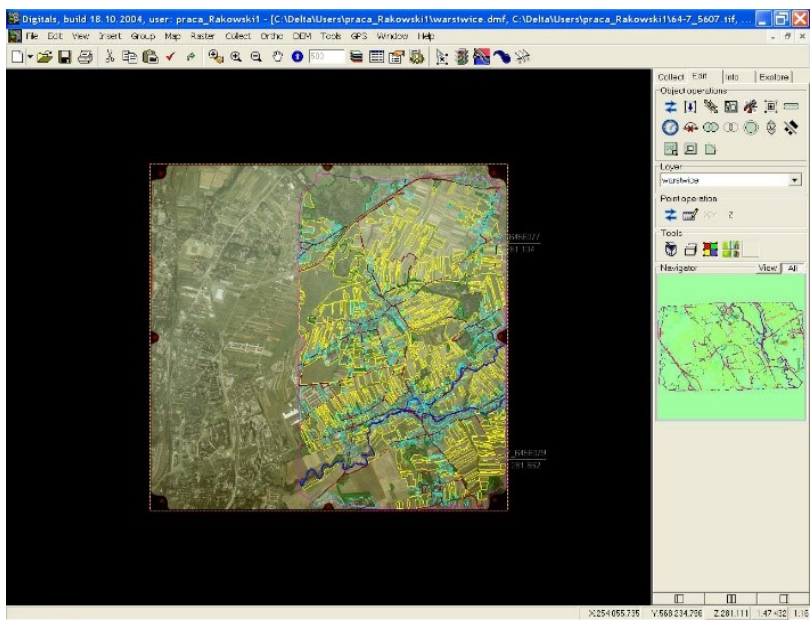

Fig. 4. Vectorization of the stereogram using digital station "Delta".

\subsection{Performance of images orientation}

Internal orientation, aimed to transform coordinates from the pixel system to the fiducial coordinates system was performed basing on previous data entry in the Camera lap. This orientation is done on a two-dimensional model, it consists in the location of the apparent measurement mark in the middle of the picture of fiducial mark. To proceed with the orientation it is 
necessary to from the Models Module the Models Model lap, and then inner orientation. The first step is to set the mark at the appropriate point in the left image, then hold down the Ctrl key, and repeat this action in right image. Pressing the right mouse button confirms the position of "apparent measurement mark". Photogrammetric Station itself imposes order to carry out this operation. After setting all the points, we get a report that indicates the accuracy, if it is too low, it is possible to improve a particular point until you reach the minimum permissible errors. Next, a mutual orientation of the images was performed. This activity was aimed at orientation pictures with each other, what is obtained by removing transverse parallax and the transformation of the fiducial coordinates to the model coordinates.

From a technical point of view, acceding to complete this orientation, it is necessary to select the Model lap, and then relative orientation. The standard measurement is performed on six points, called Gruber points, the best area of the points distribution is indicated by the photogrammetric station. And the operator decides on the selection of specific points, it must be remembered that these points were in proposed by the software area and that they do not coincide with the photo points. Orientation results are written to the report.

In the next stage of the work an absolute orientation of the pair of images was performed. This activity was necessary to transform coordinates from a model system to the surveying system, in which further measurements were made. This orientation is done using minimum three control points which have be input in the program Ground Models lap.

In order to improve the accuracy of orientation relative to the geodetic system, the absolute orientation of this study used four control points. Implementation of absolute orientation was performed on a threedimensional model. First the Model lap was chosen, then the absolute orientation. Aerial photo (aerial) measurement method and the stereo model method of orientation were selected. In the beginning it is important to set the glasses in stereo mode (for this purpose it is necessary to select from control the menu, and then OpenGL Glasses). Using the "apparent surveying mark" the situational and altitude location is determined for specified by the program GSP fotopoints.

An important step for the preparation of DTM was data vectorization. It was made using the Mapping lap. First, the relevant thematic layers were created together with a choice of relevant attributes, such as color, thickness and style of the line.

The following thematic layers were created: the scope, forests, roads, water, buildings, meadows and pastures, slopes and contours. Layers of Digital Elevation Model and Triangulated Irregular Networks are created automatically when the relevant program functions are applied. The stereogram vectorization was carried out using a three-dimensional model. To apply it is necessary to choose Stereo Glasses (Open GL) in the program options in the Hardware tab. The final result of the work was vectorization of an area of approximately 1665 hectares. The next stage of the study was to create DTM. Subsequently the triangle mesh - TIN was generated. In creation of a grid of triangles all the layers that have been previously established are involved. In order to take them into account, in the window of management the layers the status must be selected to edit, then go to the Edit lap and select all objects vectorized. Meshing TIN can be created on the basis of DEM options - Create TIN. Irregular triangular mesh is generated on an automatically created new layer named: Triangulated Irregular Networks.

The last phase of work using digital station Delta was the creation and smoothing of the contours. Generating of contour lines is executed after using Raster DTM option - Build Contour lines and passing the appropriate contour lines interval contour lines. The project used cutting interval of $2.5 \mathrm{~m}$. Created contours shpulb smoothed with the Smooth command, and then removed from the built-up areas, forests, slopes, roads and waters.

\section{Creation of a model of the terrain and flood zones models using the surfer software}

Surfer is a full-function 3D visualization, contouring and surface modelling package by Golden Software, that runs under Microsoft Windows. It is a grid-based graphic program interpolating irregularly spaced $\mathrm{XYZ}$ data into a regularly spaced grid [23]. In this elaboration all vectorized on photogrammetric station "Delta" situational details make the model, namely forests, meadows and pastures, built-up areas, water, roads and slopes. Digital Station allows saving the project to a text file in which the vectorized objects are being broken down into sections with appropriate geodetic coordinates. The structure of the text file generated by the "Delta" needs improvement, because in each layer there are listed objects and point coordinates are in them. Surfer in order to begin creation of the model, needs a continuous record of points separated by a space or a tab. The removal of unnecessary lines was performed using Microsoft Excel. Terrain model was developed on the basis of 27187 points. Model of the river was built on the basis of points obtained from the digitalization, plus the corresponding value of flood zone -2 and $5 \mathrm{~m}$. In the window it is necessary to choose the right method to create a grid, for this project the radial method was used. In the elaboration three models of grids were created: for the land surface, for the rivers with the water level higher by $2 \mathrm{~m}$ and for the river in the state higher by 5 $\mathrm{m}$. All grids were smoothed using a Gaussian filter. Creation of the 3D model is done using the option New 3D Surface. After its activation, it is necessary to enter the path to the smoothed and improved grid squares. The Surfer enables application and penetration of several models, but note that the new model must be located in an existing map (Fig. 5). After the models are created it is possible to improve the graphic and descriptive elements. Fig. 5 shows the DTM with the flood zones, created for the study area. 


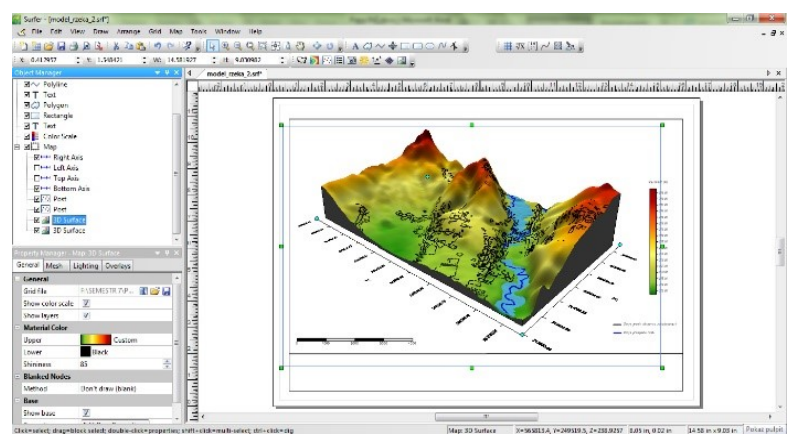

Fig. 5. Creation of the 3D visualization of the terrain model.

\section{Influence of destruction caused by the high water on the cadastral and the landscape value of the flooded areas}

The aim of the study was achieved through the creation of DTM and determining areas of potential flood risk in the Valley Prądnik. On the basis of generated model the areas most vulnerable to the destructive effects of an increase in water level of the river about $2 \mathrm{~m}$ and $5 \mathrm{~m}$ were estimated.

Flood risk affects more than $80 \%$ of the cadastral plots located on the border or in the immediate vicinity of the river Prądnik. Detailed results will be the subject of a separate publication.

The effects of flooding can have an irreversible, degradation impact on the landscape and cadastral values of flooded areas. This applies to both arable land and many existing historic architectural and engineering objects or the unique forms of the natural landscape in the Ojców National Park.

Particularly at risk are the areas in the vicinity of the spring of the river Pradnik in the cadastral commune of Suloszowa and the Zielonka commune. On the other hand, in the Skała commune, where the river has a very irregular coastline surrounded by lush greenery and is located between the high limestone cliffs, the most vulnerable to damage are surroundings of the Chapel "On The Water".

The subject of the research was a selected section of the Prądnik river. A comparison was made of cadastral maps, maps from the Austrian cadaster and land reclamation maps. The changes the course of the riverbed for over 100 years were examined. The study was based on overlaying rasters of cadastral and reclamation maps, and then redrawing the course of the riverbed basing on the borders of cadastral plots. Subsequently those data were compared with the course of the riverbed according to aerial photographs posted on the site geoportal2.

The examined section of the Prądnik river of approx. $2.5 \mathrm{~km}$ is located in the Zielonki and flows through the villages Pękowice and Zielonki. Over the entire length the section, the riverbed strongly meanders. On the definitely greater part of the study area around the river there are mostly farmland, and the course of river is natural.

The study showed that the riverbed has changed quite significantly. Definitely the largest displacements in comparison to the current course of the river are shown on Austrian cadastral maps. Differences in some places reach up to $35 \mathrm{~m}$. This is due to the fact that these maps were created at the earliest and show the course of over 100 years before. Reclamation maps showed smaller differences. In contrast, the riverbed on new cadastral maps almost perfectly coincides with the riverbed shown in aerial photographs on the geoportal2 site which indicates on a relatively low activity of the river.

Prądnik river is considered one of the few rivers which run is natural almost on its entire length (except for the section flowing through the territory of the city of Krakow). Although looking at the fragment of the river shown in Fig.7 it can be concluded that this part of the river was changed as a result of human activities. In the aerial photo it can be seen, that in the place where previously there was the riverbed, there is no trace, that it ran at the original site, and at the moment there is arable land there. Therefore, it can be concluded with a high probability, that the course of the riverbed has been artificially regulated. While at the remaining part of the test section the flow changes of Pradnik are not so significant and are associated with natural processes.

One of the consequences of the fact, that the river is not in any way regulated, is the increasing siltation of the bottom, and thus reduction of its depth. The result is a quite often occurrence of local floodings, caused by sudden and heavy precipitations. They occur most often just in the Zielonki commune.

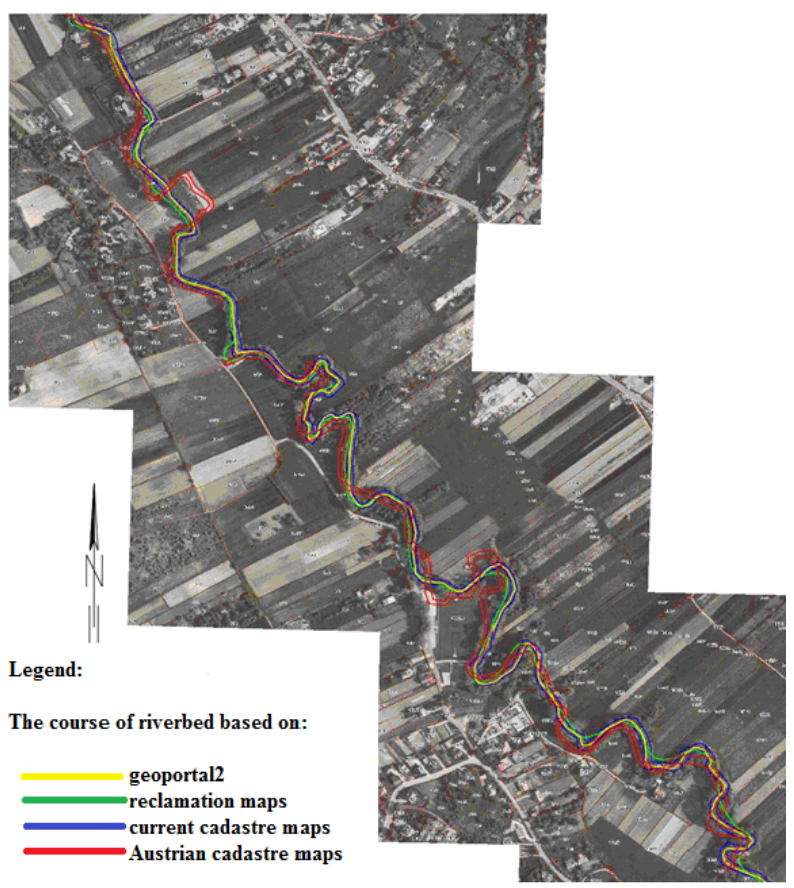

Fig. 7. The course of the Praqdnik river on the test section on orthophotomap from geoportal2 [24].

\section{Conclusions}

The advantage of using photogrammetric methods is the possibility of work in chamber conditions, which allows independence from weather conditions. Making aerial 
photographs although preceded by very long preparation, provides a large amount of materials giving coverage over areas such as several communes. The accuracy of the measurements to create a Digital Terrain Model is very high. Progress has been made in the construction of the measuring cameras allows to perform photogrammetric digital images that are free from errors caused by photos scanning.

Due to the location of many of the built-up areas in river valleys, the definition of flood zones based on digital terrain model with elements of its coverage, becomes the basis for municipalities and counties to counteract the effects of floods.

Basing on the described methodology for the creation of the DTM simulation of the flood zones can be made for each commune, as well as full monitoring of vulnerable areas.

\section{References}

1. M. Kemblowski, et al. Risk modelling with Bayesian Networks - case study: construction of tunel under the Dead Vistula River in Gdansk, Procedia Engineering, 196, pp. 585-591 (2017)

2. Regulation of the Minister of Internal Affairs and Administration dated November 3, 2011r. regarding the databases on aerial and satellite imagery and orthophotos and digital terrain model (Journal od Laws No. 193, item 1287) (2011)

3. R. Weibel, M. Heller, Digital terrain modelling. In Maguire, D. J., et al. (eds.), Geographical Information Systems: Principles and Applications. London: Longman (1991)

4. I. V. Florinsky Errors of signal processing in digital terrain modelling International Journal Geographical Information Science Volum 16, pp.475-501 (2010)

5. J. Kocyła, Visualization, methodology and proposals for the use of the numerical terrain model in geology on the example of the spatial model of the Warta River section, Warszawa: Surveying Review 45, pp. 211-214 (1997) (in Polish)

6. K. Kraus, J. Otepka,. NMT Modelling and Visualization - The SCOP Approach. 'Photogrammetric Week 05', Wichmann Verlag, Heidelberg, pp. 241-252 (2005)

7. K. Pyrchla, A. Inglot, J. Pyrchla, Fuzzy Sets in the GIS Environment in the Location of Objects on the Surface of Water Bodies, DOI: 10.1109/BGC.Geomatics.2017.44, Publisher:IEEE, BGC Geomatics (2017)

8. O. Dorozhynskyy, T. Wrona. Basics of photogrammetry, Publisher of the Lviv Polytechnic, Kraków - Lwów (2003)

9. N. El-Sheimy et al. Digital Terrain Modeling: Acquisition, Manipulation And Applications, Artech House (2005)

10. Braun, H. McQueen, M. Sambridge. Geophysical parametrization and interpolation of irregular data using natural neighbours, Geophys. J. Int. 122, pp. 837-857 (1995)

11. K. Bobkowska, et al. Implementation of Spatial Information for Monitoring and Analysis of the Area Around the Port Using Laser Scanning Techniques, PMR, 24, pp 10-15 (2017)

12. A. Janowski, et al. Airborne and mobile laser scanning in measurements of sea cliffs on the southern Baltic, GeoConference-SGEM (2015)

13. Directive 2007/60/EC of the European Parliament and of the Council of 23 October 2007 on the assessment and management of flood risks (Official Journal of the European Union, L288), pp. 27 (2007)

14. Z. Zwoliński, On the homology of geoinformatic terminology. [In:] GIS - water in the environment, Poznań: Bogucki Scientific Publisher, pp. 21-30. ISBN 978-83-6132091-3 (2010)

15. Water Law dated July 20, 2017 (Journal od Laws 2017, item 1566), (2017)

16. M. Szydlowski, W. Szpakowski, P. Zima, Numerical simulation of catastrophic flood: the case study of hypothetical failure of the Bielkowo hydropower plant reservoir, Acta Geophysica, 61(5), pp. 1229-1245 (2013)

17. L. Hai-Min et al., Flood risk assessment in metro systems of mega-cities using a GIS-based modelling approach, SC OF THE TOT ENVIR, 626, pp. 10121025 (2018)

18. E. Drożdżal, Flood hazard zones, Gospodarka wodna, 11, pp. 425 - 427 (2006)

19. V. B. Mitkova et al. Reconstruction and post-event analysis of a flash flood in a small ungauged basin: a case study in Slovak territory, Natural Hazards, 92, pp. 741-760 (2018)

20. W. Szpakowski, M. Szydlowski, Evaluating the Catastrophic Rainfall of 14 July 2016 in the Catchment Basin of the Urbanized Strzyza Stream in Gdansk, Poland, Pol Jour of Envir St, 27, pp. 861869 (2018)

21. Regulation of the Minister of Regional Development and Construction dated. March 29, 2001 on the registration of land and buildings (Journal od Laws No. 38, item 454), (2001)

22. P. van Oosterom, E. Fendel Proceedings of $4^{\text {th }}$ International Workshop on 3D Cadastres, Dubaj, ISBN: 978-87-92853-21-8 (2014)

23. J. Redl, V. Valikova, J. Antl, Modelling of Terrain Surface Acta Technologica Agriculturae 1 Nitra, Slovaca Universitas Agriculturae Nitriae, pp. 1720, (2014)

24. http://mapy.geoportal.gov.pl/imap/ 